\title{
Evaluation of the visual stress grading standard on French Spruce (Picea excelsa) and Douglas-fir (Pseudotsuga menziesii) sawn timber
}

\author{
Guillaume Roblot*, Damien Coudegnat, Laurent Bleron, Robert Collet \\ LaBoMaP, Groupe Matériaux et Usinage Bois, CER ENSAM Cluny, 71250 Cluny
}

(Received 3 April 2008; accepted 19 August 2008)

Keywords:

Douglas-fir /

Spruce /

visual stress grading /

MOE /

MOR

\begin{abstract}
- In this paper an evaluation of the visual grading standard for softwood sawn timber was made. - In order to do so, visual grading according to EN 518 and theoretical grading according to EN 338 and EN 384 (measurements of MOE, MOR and density) were applied to lumber. Two batches of 111 and 102 French boards were graded, respectively, of Spruce (Picea excelsa) and Douglas-fir (Pseudotsuga menziesii). For the visual grading the most discriminant criterion was noted: knots, cracks, wane, etc.

- Finally, the results of the two grading methods were compared, and it was shown that the visual stress grading gave quite low results for our two French species.
\end{abstract}

\begin{abstract}
Résumé - Évaluation de la norme de classement mécanique visuel sur des sciages français d'épicéa (Picea excelsa) et de Douglas (Pseudotsuga menziesii).

- Cette étude a pour objectif d'évaluer la pertinence des résultats du classement visuel de la norme EN 518 sur des sciages de bois français.

- Pour cela 111 pièces d'épicéa (Picea excelsa) et 102 pièces de Douglas (Pseudotsuga menziesii) ont été classées en suivant d'une part le classement visuel de la norme EN 518 et en réalisant d'autre part un classement dit théorique suivant les normes EN 338 and EN 384 (mesure du Module de Young (MOE), contrainte de rupture (MOR) et masse volumique). Pour le classement visuel, le critère le plus discriminent a été relevé pour chaque planche : nœuds, fentes, flaches.

- Finalement une comparaison entre les résultats des deux techniques de classements a été réalisée, et le faible rendement du classement visuel sur nos deux essences à été montré.
\end{abstract}

\section{INTRODUCTION}

Since July 2007 all lumber used in structural applications has to be graded according to precise specifications. There are two main ways of grading lumber (Kretschmann and Hernandez, 2006). The first method is visual grading according to the standard EN 518 (CEN, 1995) which corresponds to the standard NF B 52001 for France (AFNOR, 2007). The other method is grading by machines, also called machine strength grading. However, these kinds of machines are quite expensive, and small or middle-size companies like most French sawmills cannot afford such expensive systems.

However, some studies have shown that the rules of visual grading are not really adapted to French softwood. Actually, the standard EN 518 has been established from rules which were set out in the first place for Spruce from the north of Europe. Then it was adapted for other species and other locations, such as the French Douglas-fir, for example. Some studies have shown that visual grading tends to underestimate

*Corresponding author: roblot@luxscan.com the mechanical characteristics of Douglas-fir lumber (Lanvin, 2005). Douglas-fir is, indeed, a species that grows very rapidly. Consequently, it has very large annual rings and bigger knots. Other studies have shown bad grading accuracy for Spruce too (Rouger and Guinard, 2005). These points are a disadvantage for French lumber and this is one of the reasons why French companies import structural wood from the Scandinavian countries or Germany.

In order to show that visual stress grading does not give good results on French species, an evaluation of this grading was done on French lumbers. Both visual grading and theoretical grading were carried out on Spruce and Douglas-fir sawn timber from a French sawmill.

\section{MATERIALS AND METHODS}

\subsection{Materials}

For this study French lumber of Douglas-fir and Spruce was used. We do not have much information about the origin of the wood, except that it came from near the sawmill which is in Sougy-sur-Loire (58, France) and from quite small logs since almost every board was 
Table I. 111 Spruce and 102 Douglas-fir boards' description.

\begin{tabular}{clcc}
\hline & & $\begin{array}{c}\text { Density } \\
\mathrm{kg.m^{3 }}\end{array}$ & $\begin{array}{c}\mathrm{MC} \\
\%\end{array}$ \\
\hline \multirow{2}{*}{ Spruce } & Mean & 390 & 11.3 \\
& Std. Deviation & 29 & 1.5 \\
\multirow{2}{*}{ Doug. } & Mean & 474 & 11.8 \\
& Std. Deviation & 49 & 1.3 \\
\hline
\end{tabular}

near the pith and had sapwood on the other side. The boards were then kept at $12 \% \mathrm{MC}$ during the whole time of the study. All the lumber was $43 \mathrm{~mm} \times 135 \mathrm{~mm} \times 3 \mathrm{~m}$. The length of all boards was $3 \mathrm{~m}$. The number of boards and characteristic values are shown in Table I.

\subsection{Visual grading}

The visual grading was done according to the standard NF B 52001 with special criteria according to species (Douglas-fir and Spruce). The standard takes into account the width of annual rings, dimensions of knots, cracks, resin pockets, inbark, grain angle, wane and blue stain. The standard defines three limit values for each kind of defect, which give three grading classes called STI, STII and STIII (corresponding to C30, C24 and C18 of EN 338 (CEN, 2003) for Spruce and Douglas-fir (CEN, 1998)). The two batches of 213 specimens were graded according to the standards and for each one the most discriminant criterion was recorded.

\subsection{Theoretical grading}

According to EN 338 a lumber grade is determined from three different parameters: density, modulus of elasticity (MOE) and modulus of rupture (MOR). The density was computed from dimensions and weight measurement. In order to obtain the MOE and MOR we ran 4-points-edgewise bending tests according to EN 408 specifications (CEN, 1995).

From that point all the necessary elements were available to establish the grading according to the standards EN 384 (CEN, 2004) and EN 338. Boards are classified into four different grades according to MOR values, the minimum value calculated from the $5 \%$ fractile and coefficients $\mathrm{k}_{\mathrm{s}}$ and $\mathrm{k}_{\mathrm{v}}$. Then for each group the mean value of the MOE is computed and compared with values from the EN 338 table. If the mean value is under the limit of the grade, boards are downgraded in order to get a correct mean value. Density values were checked according to EN 384 but they were higher than the limit for each board.

\section{RESULTS AND DISCUSSION}

Firstly, the results of the two grading methods will be presented separately and then comparison of the results will be made.

\subsection{Visual grading}

\subsubsection{Grading results}

Repartitions for Douglas-fir and Spruce in each class are shown in Figure 1. As can be seen, very few boards are graded

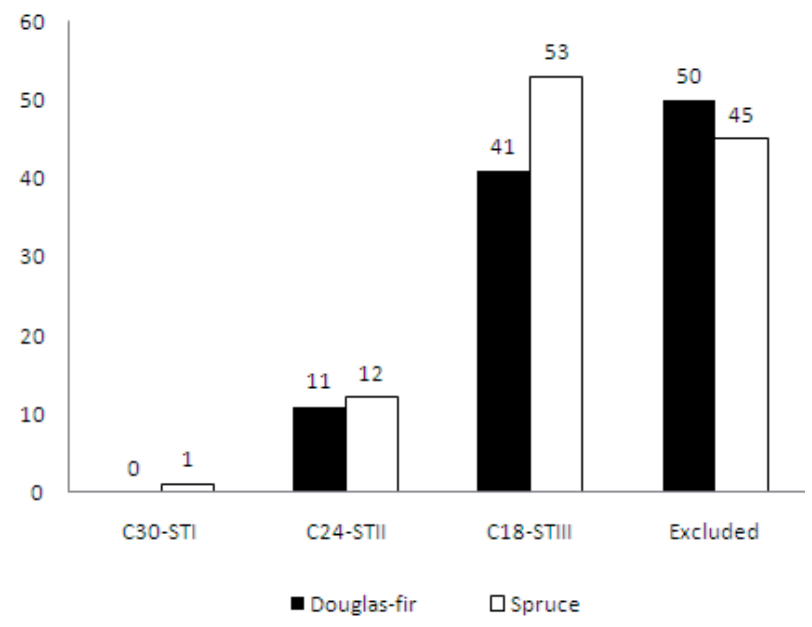

Figure 1. Number of boards for each grade according to visual grading.

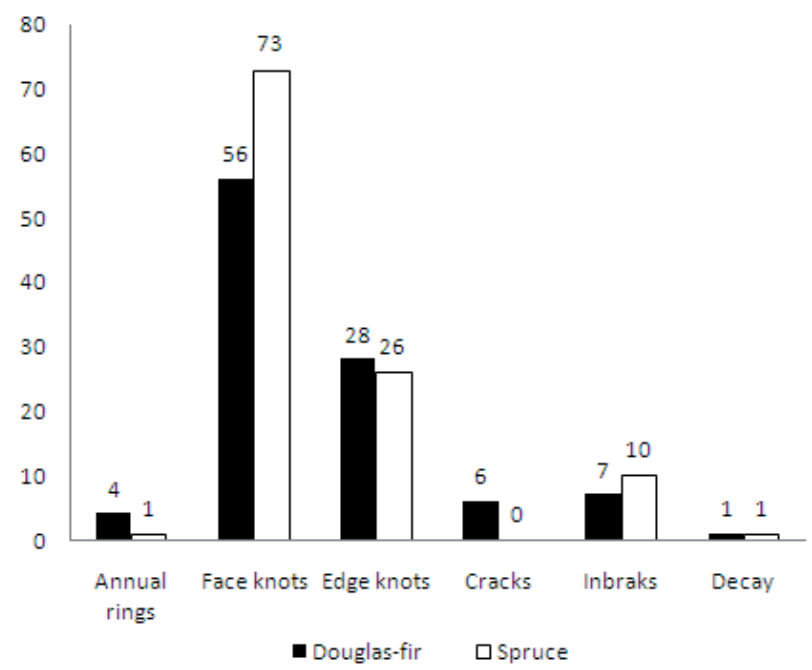

Figure 2. Repartition of the most disciminant criteria.

in high classes (C30 and C24). In fact, according to visual grading almost half of the lumber are in C18 and the other half cannot be used for structural applications (lower than C18). One can also notice that the repartition between grades is almost the same for Spruce and Douglas-fir lumber.

\subsubsection{Complementary results}

During the visual grading for each lumber the most discriminant criterion was recorded (the one which gives the grade of the lumber). As can be seen in Figure 2, knot dimension (faces plus edges) is, in most cases, the most important criterion. Eighty-four out of 102 lumbers (82\%) for Douglas-fir and 99 out of 111 lumbers (89\%) for Spruce were graded thanks to knots. Other criteria are much less significant: one can notice, however, that 4 Douglas-fir lumbers were downgraded due to width of annual rings and only one of Spruce. In the same way, 6 Douglas-fir specimens had cracks and none of the Spruce 
Table II. Spruce measurement results.

\begin{tabular}{lccc}
\hline & $\begin{array}{c}\text { MOE } \\
M P a\end{array}$ & $\begin{array}{c}\text { MOR } \\
M P a\end{array}$ & $\begin{array}{c}\text { Density } \\
\mathrm{kg} \cdot \mathrm{m}^{3}\end{array}$ \\
\hline Mean & 9587 & 28 & 390 \\
Std. Deviation & 1515 & 10 & 29 \\
Minimum & 6955 & 11 & 319 \\
Maximum & 13522 & 61 & 480 \\
\hline
\end{tabular}

Table III. Douglas-fir measurement results.

\begin{tabular}{lccc}
\hline & MOE & MOR & Density \\
& $M P a$ & $M P a$ & $\mathrm{~kg} \cdot \mathrm{m}^{3}$ \\
\hline Mean & 12138 & 35 & 474 \\
Std. Deviation & 2581 & 12 & 49 \\
Minimum & 7340 & 14 & 390 \\
Maximum & 20687 & 74 & 636 \\
\hline
\end{tabular}

specimens. This result is interesting because knots are the easiest defects to see, especially in an industrial grading process.

\subsection{Theoretical grading results}

The statistical results of measurement for the theoretical grading (MOE, MOR and density) are shown in Tables II and III. First, one can note that the mean values correspond to what one can find in the bibliography (CTBA, 1986), (Renaudin and Breysse, 1998). This means that the samples tend to be representative. The mean values of MOE, MOR and density are higher for Douglas-fir than for Spruce. Finally, one can note that within each species standard deviation is quite high.

The results of the theoretical grading computed thanks to MOE, MOR and density measurements, according to EN 338 and EN 384, can be found in Figures 3 and 4. As here, repartitions between grades are very different for Douglas-fir and for Spruce. First, only 17 lumbers out of 102 (16\%) are under the C18 grade for Douglas-fir when 72 out of $111(65 \%)$ are for Spruce. Secondly, the grade with the most lumbers is C30 (62\%) for Douglas-fir and C18 for Spruce $(65 \%)$. We can thus say that for our samples the batch of Douglas-fir lumbers is of much higher quality than Spruce from a mechanical point of view. This fact was not shown by the visual grading results, which gave equivalent characteristics for both species.

\subsection{Comparison between visual and theoretical grading}

In order to make a comparison between the two grading results, they are presented in Figures 3 and 4. One can first notice that for both species there are a lot more excluded boards by the visual grading than there should be (45 instead of 13 for Spruce and 50 instead of 2 for Douglas-fir). Secondly, the results for the two species are quite different for higher grades. For Spruce, where the main grade is $\mathrm{C} 18$, we can see that the visual grading results are almost equivalent to the theoretical

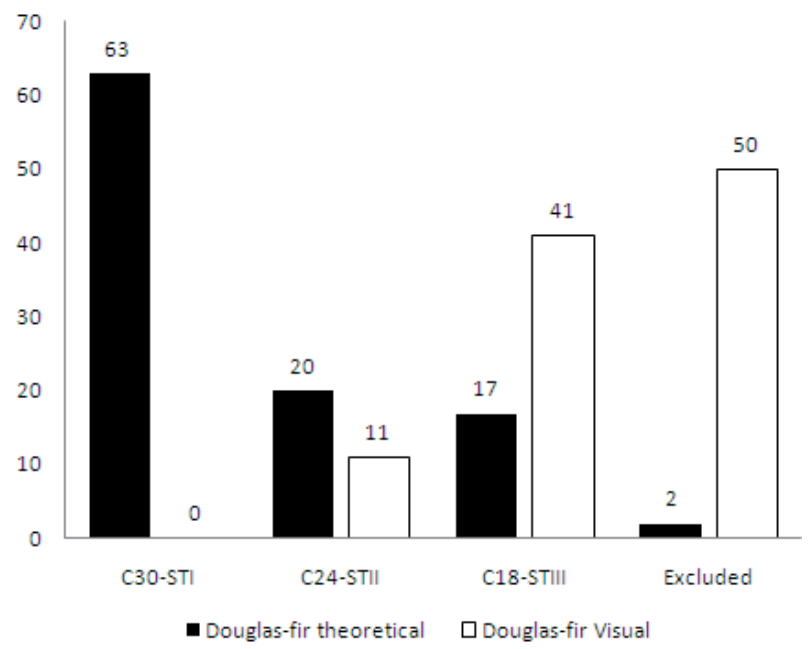

Figure 3. Comparison of visual and theoretical grading for Douglasfir.

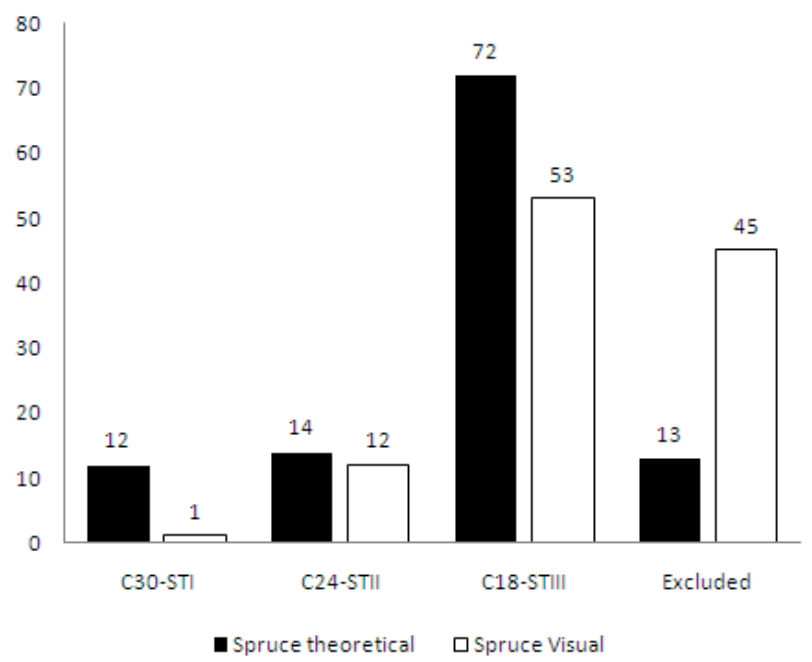

Figure 4. Comparison of visual and theoretical grading for Spruce.

grading results. However, for Douglas-fir, for which the main grade is $\mathrm{C} 30$, the visual grading gives no $\mathrm{C} 30$ board and 41 $\mathrm{C} 18$ boards. The grade repartition actually looks the opposite for visual and theoretical grading.

In order to make a more accurate comparison the board-byboard grading results have to be compared. Size matrices, as they are defined in EN 14081-2, are used. Tables IV and V are size matrices for Douglas-fir and Spruce batches. By summing the value of the diagonal of the matrices we get the number of well-graded boards. For Spruce there are $27 \%$ well-graded lumbers and only $7 \%$ for Douglas-fir. The next thing that one can notice is the number of over-graded lumbers. For both species this number is quite small: only 1 board of Douglasfir is over-graded and 7 for Spruce. Finally, the number of down-graded boards is very high, $67 \%$ for Spruce and $92 \%$ for Douglas-fir. 
Table IV. Size matrix for Spruce boards.

\begin{tabular}{lccccc}
\hline Th. \Visual & C30 & C24 & C18 & Excl. & Sums \\
\hline C30 & 1 & 6 & 19 & 14 & 40 \\
C24 & 0 & 3 & 12 & 9 & 24 \\
C18 & 0 & 2 & 18 & 14 & 34 \\
Excluded & 0 & 1 & 4 & 8 & 13 \\
Sums & 1 & 12 & 53 & 45 & 111 \\
\hline
\end{tabular}

Table V. Size matrix for Douglas-fir boards.

\begin{tabular}{lccccc}
\hline Th. $\backslash$ Visual & C30 & C24 & C18 & Excl. & Sums \\
\hline C30 & 0 & 9 & 31 & 23 & 63 \\
C24 & 0 & 1 & 6 & 13 & 20 \\
C18 & 0 & 1 & 4 & 12 & 17 \\
Excluded & 0 & 0 & 0 & 2 & 2 \\
Sums & 0 & 11 & 41 & 50 & 102 \\
\hline
\end{tabular}

\subsection{Discussion}

Three kinds of results can actually be defined for the grading of lumber: those which are well graded, over-graded or downgraded. In each case, the consequences are different. On the one hand, downgraded lumber leads to the underestimation of the price of the piece of wood. Thus, the people who made the grading lose money. On the other hand, over-graded lumber is dangerous because it will be used at loads it cannot handle. As a consequence, buildings can be damaged or even collapse.

As we saw, the results are a little different for Douglas-fir and Spruce lumbers. However, for both species the number of over-graded boards is very limited. This is very important to note because it shows that applying the visual grading standard EN 518 to French lumber of Spruce and Douglas-fir is not a security risk. However, for both species there are a lot of downgraded boards. This is especially true for Douglas-fir, but since we did not get a lot of high-class (C30 and C24) Spruce lumbers we cannot really make a comparison. Nevertheless, we can assert that French companies which are using visual grading for the two species of our study are losing some money.

\section{CONCLUSION}

In this paper, a comparison was made between results of visual grading according to EN 518 and theoretical grading done according to EN 338 and EN 384 on 213 French lumbers. The main result of this study is that visual grading according to EN 518 does not seem very accurate for French Spruce and Douglas-fir sawn timber. Even if the amount of over-grading is quite limited, the cost of downgraded boards would be quite significant for companies which are grading wood.

These results tend to demonstrate the limits of visual grading rules and are in accordance with the results of previous studies in this field (Lanvin, 2005; Rouger and Guinard, 2005). It is important to notice that the visual grading was done in optimal conditions, thus quite a long time was taken for each lumber (several min), and we could see the lumber from each end. This is actually never the case in an industrial context. Moreover, in order to get more representative results, tests should to be run on other dimensions and with different origins for the lumbers.

Finally, two methods could be used to manage the weakness of the standard. First, the grading rules could be improved to correspond better with French species' characteristics. We actually know that French boards generally have more knots than north European ones, but they do not seem to affect the mechanical properties that much. The other solution would be to use machine stress grading. This solution is certainly more expensive for grading companies. Nevertheless, it gives more accurate results (Blass and Frese, 2004; Boström, 1994; Hanhijärvi et al., 2005; Lycken, 2005) for each species and money can be saved thanks to more accurate grading results.

Acknowledgements: We wish to thank J.C. Sève and S. Vives from Monnet-Sève sawmills who provided us with the two batches of boards. Acknowledgments also go to people from LaBoMap, especially J.C. Butaud who helped us during the tests. Finally, we thank L. Brancheriau from CIRAD, who assisted us with the data exploitation.

\section{REFERENCES}

AFNOR, 2007. NF B 52001 - Regulations governing the use of timber in structure - Visual classification for the use of the main coniferous and deciduous wood types in structures.

Blass H.J. and Frese M., 2004. Combined visual and machine strength grading. Holz Roh-Werkst. 62: 325-334.

Boström L., 1994. Machine strength grading. Comparison of four different systems. SP Report, 49.

CEN, 2005. EN14081 - Timber structures - Strength graded structural timber with rectangular cross section.

CEN, 2004. EN 384 - Structural timber. Determination of characteristic values of mechanical properties and density.

CEN, 2003. EN338 - Structural Timber - Strength classes.

CEN, 1998. EN1912 - Structural timber - Strength classes - Assignment of visual grades and species.

CEN, 1995. EN408 - Timber structures - Structural timber and glued laminated timber - Determination of some physical and mechanical properties.

CEN, 1995. EN518 - Structural timber - Grading - Requirements for visual strength grading standards.

CTBA, 1986. Le Douglas. Cahier du Centre Technique du Bois et de l'Ameublement, 118: 85-94.

Hanhijärvi A., Ranta-Maunus A., and Turk G., 2005. Potential of strength grading of timber with combined measurement techniques. Espoo, VTT Publications, 568, 88p.

Kretschmann D. and Hernandez R., 2006. Grading timber and glued structural members. In: Walker J. (Ed.), Primary wood processing 2nd ed., pp. 339-390.

Lanvin J.D., 2005. Vers une optimisation du classement pour la résistance des fortes sections Douglas. DOUGLAS Infos, 11.

Lycken A., 2005. Comparison between automatic and manual quality grading of sawn softwood. For. Prod. J. 56: 13-18.

Renaudin P. and Breysse D., 1998. Anatomic parameters and failure behaviour in spruce lumber. Mat. Stru. 32: 311-318.

Rouger F. and Guinard D., 2005. Is Scandinavian timber superior to French timber: A close scrutiny. Rev. For. Fr. 57: 85-94. 